\title{
PESQUISA DE ALGUNS GRUPOS DE MICRORGANISMOS EM SALADAS COM MAIONESE ADQUIRIDAS EM RESTAURANTES, LANCHONETES E "ROTISSERIES"
}

\author{
Sirdeia Maura Perrone Furlanetto* \\ Ananias Azevedo Lacerda** \\ Maria Lucia Cerqueira-Campos**
}

\begin{abstract}
FURLANETTO, S.M.P. et al. Pesquisa de alguns microrganismos em saladas com maionese adquiridas em restaurantes, lanchonetes e "rotisseries". Rev. Saúde públ., S. Paulo, 16:307-16, 1982.
\end{abstract}

RESUMO: Em vinte amostras de saladas com maionese foram efetuadas as contagens de bactérias mesófilas e psicrofilas, Staphylococcus aureus, Bacillus cereus, bolores e leveduras, a determinação do Número Mais Provável (NMP) de bactérias coliforme totais de Escherichia coli e de estreptococos fecais, bem como a pesquisa de salmonelas. A contagem de bactérias mesófilas variou de $2,64 \times 10^{4} \mathrm{a} \geqslant 3 \times 107 / \mathrm{g}$ do produto. Quanto às bactérias psicrófilas, as contagens variaram de $<10$ a $\geqslant 3 \times 107 / \mathrm{g}$. Para S. aureus, as contagens oscilaram de $<10^{2}$ a $4 \times 105 / \mathrm{g}$ do alimento, enquanto que para $B$. cereus os números mínimo e máximo foram $<10^{2}$ e $\geqslant 3$ $x$ 104/g, respectivamente. Para bolores e leveduras, as contagens variaram de $7,1 \times 10^{2}$ a $3,7 \times 106 / \mathrm{g}$. Com relação ao NMP de coliformes totais e estreptococos fecais, os resultados obtidos mostraram-se compreendidos entre $<0,03$ e $\geqslant 4,3 \times 105 / \mathrm{g}$. Quanto ao NMP de $\mathbf{E}$. coli os números mínimo e máximo obtidos foram respectivamente de $<0,03 \mathrm{e} \geqslant 2,4 \times 104 / \mathrm{g}$ de salada com maionese. Tais constataçóes indicam a ocorrência de contaminação inclusive por microrganismos de origem fecal. Todas as amostras revelaram-se negativas para bactérias do gênero Salmonella.

UNITERMOS: Alimentos, contaminação. Microbiologia.

\section{INTRODUÇAO}

Nos últimos 20 a 30 anos tem ocorridu, a nivel mundial, aumento cada vez maior do número de estabelecimentos públicos de alimentação. Isto prende-se, principalmente, ao aumento da população e, portanto, ao número de pessoas que procuram tais estabelecimentos a fim de neles fazerem suas refeições ou adquirirem alimentos pre- parados, para serem consumidos no próprio domicílio.

Assim, em estabelecimentos públicos de alimentação, na Inglaterra, em 1950, eram consumidas um milhão e trezentas mil refeições por semana, sendo, atualmente, quase impossivel se estabelecer, nesse país, uma estimativa a respeito. $\mathrm{Na}$ Suiça, cerca de

* Do Departamento de Microbiologia e Imunologia do Instituto de Ciências Biomédicas da USP "Setor Saúde Pública" - Av. Dr. Arnaldo, 715 - 01255 - São Paulo, SP - Brasil.

* Do Departamento 3 de Farmácia Qualitativa da Faculdade de Farmácia da Universidade Federal da Bahia - Campus da Federação - 40.000 -. Salvador, BA - Brasil. 
FURLANETTO, A.P. et al. Pesquisa de alguns microrganismos em saladas com maionese adquiridas em trestaurantes, lanchonetes e "rotisseries". Rev. Saúde públ., S. Paulo, 16:307-16, 1982.

2 milhões de pessoas tomam pelo menos uma refeição fora do domicilio. Na Suécia são servidas, em restaurantes, aproximadamente 4 milhões de refeições por dia, enquanto que, tal estimativa, na Alemanha Ocidental, atinge a 18 milhões (Brodhage e Anderhub 4, 1975).

No Brasil, em São Paulo, bem como em outras cidades brasileiras, é comum também se fazer pelo menos uma refeição fora de casa, sendo a salada com maionese um dos alimentos comumente consumidos. Este alimento é basicamente composto por legumes cozidos, verduras e creme de maionese. Sendo preparado a partir de vegetais, estes podem, sobretudo os crús, conter na sua superfície microrganismos oriundos da água, do solo, de adubos e do ar. Assim, os ingredientes devem ser submetidos a uma lavagem cuidadosa, principalmente aqueles que serão posteriormente adicionados crús aos já cozidos. Deve-se levar em conta, também, que os ingredientes cozidos são picados após o cozimento e, portanto, sujeitos a contaminações oriundas dos manipuladores e utensilios.

Segundo Smittle 22 (1971), existe uma crença poputlar de que saladas adicionadas de molhos ou maionese deterioram-se rapidamente podendo causar riscos à saúde do consumidor. Por outro lado, esse mesmo autor argumenta que em vegetais e carnes, que são excelentes meios para o desenvolvimento de bactérias patogênicas, ocorre o retardamento do crescimento de salmonelas e estafilococos e a inibição da multiplicação de Bacillus cereus e Clostridium perfringens, quando esses produtos são adicionados de molhos, vinagre ou maionese. Entretanto Kotaka e col.13 (1979) investigando um surto de toxinfecção alimentar ocorrido em um restaurante situado em Curitiba, Estado do Paraná, isolaram das fezes de pessoas atingidas, cêpas de Salmonella enteritidis e Salmonella typhimurium. Os autores concluiram por outro lado, que o alimento presumivelmente responsável pelo surto foi salada de batata com maionese.
Deve ser salientado que o creme de maionese, basicamente, é uma emulsão composta de azeite, ovos e vinagre. O vinagre pode exercer ação impediente do crescimento da maioria dos microrganismos, porém o azeite e, principalmente, os ovos, ao contrário, comportam-se como bons meios de cultura devido às suas propriedades nutritivas.

Assim sendo, além da microbiota dos vegetais que entram como ingredientes deste alimento, o descuido das normas habituais de higiene durante o seu preparo e manuseio por parte de manipuladores, e as condiçōes em que são comumente armazenados estes produtos, fazem com que os microrganismos ncles presentes possam vir ou não a causar alterações no alimento $2,7,8,10,11,12,14,16,19,25$ 'ou intoxicações alimentares nos seus consumidores ${ }^{26}$.

Partindo do exposto e dada a falta de investigaçōes com este tipo de alimento em nosso meio, procurou-se estudar as condições microbiológicas de saladas com maionese oferecidas ao consumo em restaurantes, lanchonetes e "rotisseries", situadas na cidade de São Paulo, através da contagem de bactérias mesófilas e psicrófilas, Staphylococcus aureus, $B$. gereus e bolores e leveduras, assim como da determinação do NMP de bactérias coliformes totais, de Escherichia coli e estreptococos fecais e da pesquisa de bactérias do gênero Salmonella.

\section{MATERIAL E METODOS}

Foram adquiridas em diferentes restaurantes, lanchonetes e "rotisseries" da cidade de São Paulo, 20 amostras de salada com maionese. Uma vez adquirida a amostra, esta era levada imediatamente ao laboratório iniciando-se logo a seguir, as análises microbiológicas. $O$ tempo decorrido entre a coleta das amostras e o inicio dos exames nunca excedeu de 60 min.

Tanto o preparo das amostras como de suas diluiçōes foram realizados segundo as técnicas recomendadas por Thatcher e Clark ${ }^{24}$ (1973). Assim, eram pesados $11 \mathrm{gr}$. 
FURLANETTO, S.M.P. et al. Pesquisa de alguns microrganismos em saladas com maionese adquiridas em restaurantes, lanchonetes e "rotisseries". Rev. Saúde públ., S. Paulo, 16:307-16, 1982.

do material, os quais eram colocados em liquidificador estéril seguido da adição de $99 \mathrm{ml}$ de água tamponada fosfatada estéril com $\mathrm{pH} 7,2$, a fim de se obter uma diluiçăo inicial de $10^{-1}$. Em seguida, procedia-se a liquidificação do material por $2 \mathrm{~min}$, e a partir desta diluição inicial preparava-se uma série de diluições decimais de $10^{-2}$ a $10^{-5}$, empregando-se frascos com rolha de borracha contendo $9 \mathrm{ml}$ de água fosfatada estéril.

Contagem padrão em placas de bactérias mesófilas e psicrófilas (American Public Health Association (APHA) 1976

Um ml de cada diluição do material a ser examinado, em duplicata, era depositado no fundo de duas séries de placas de Petri estéreis e a seguir eram vertidos, em cada placa, $15 \mathrm{ml}$ de ágar glicose-extrato levedo-triptona fundido e resfriado a $45^{\circ} \mathrm{C}$. Após a homogeneização e solidificação do agar, uma das séries era incubada a $35^{\circ} \mathrm{C}$ por $48 \mathrm{~h}$, para a contagem de bactérias mesófilas c, a outra, a $7^{\circ} \mathrm{C}$ por 10 dias para a de psicrófilas. Após a incubação eram selecionadas, de cada série, as placas contendo entre 30 e 300 colônias. Em seguida, nestas placas, procedia-se à contagem do respectivo número de colônias, o qual era multiplicado pela recíproca da diluição correspondente, a fim de obter-se o número de bactérias mesófilas e psicrófilas por grama de maionese.

Contagem de bolores e leveduras (APHA ${ }^{1}$, 1976) - O preparo das placas e o cálculo final do número destes microrganismos por grama do alimento eram realizados da mesma forma que a descrita para a contagem de bactérias mesófilas e psicrófilas, porém o meio de cultura utilizado era o ágar glicose-batata acidificado, sendo a incubação feita à temperatura de $23^{\circ} \mathrm{C}$. As leituras eram procedidas após 3 a 5 dias de incubação.
Contagem, isolamento e identificação de S. aureus (Thatcher e Clark ${ }^{24}, 1973$ )

$\mathrm{Na}$ contagem destas bactérias, $0,1 \mathrm{ml}$ de cada diluição do material a ser examinado era depositado na superfície do ágar Baird- Parker em placas de Petri. $O$ inóculo era espalhado sobre o ágar empregando-se, para tal, alça de Drigalski e, a seguir, as placas eram incubadas a temperatura de $35^{\circ} \mathrm{C}$ por 24 e $48 \mathrm{~h}$. Após a incubação, procedia-se à contagem de número de colônias, em placas contendo entre 30 e 300 colônias. Eram contadas as colônias negras, brilhantes, com zona de precipitação circundada por um halo de transparência. $O$ cálculo do número de $S$. aureus por grama de maionese era feito multiplicando-se por 10 o número de colônias contadas e a seguir multiplicando-se o resultado pela recíproca da diluição correspondente à placa de contagem.

$\mathrm{Da}$ placa de contagem, procedia-se 0 isolamento de colônias típicas, as quais eram semeadas em ágar simples inclinado. Após $24 \mathrm{~h}$ de incubação a $35^{\circ} \mathrm{C}$, eram preparados esfregaços corados pelo método de Gram, para a verificação da morfologia das cêpas isoladas. As cêpas que microscepicamente se mostravam como cocos Gram-positivos dispostos em cachos, eram submetidas às provas de verificação de produção de catalase (Baird-Parker ${ }^{3}, 1966$ ), da fermentação-oxidação da glicose, segundo técnica preconizada pelo Subcomitê Internacional de Taxonomia de Staphylococcus e Micrococcus ${ }^{23}$ (1965), da produção de DNase (Di Salvo ${ }^{5}$, 1958) e de coagulase livre de acordo com a técnica usada por Zelante ${ }^{27}$ (1974). Tais provas devem ser positivas quando se trata de S. aureus.

Contagem, isolamento e identificação de B. cereus

De cada diluição do produto, era tomado um volume de $0,1 \mathrm{ml}$, o qual era depositado na superfície de ágar gema de ovo-polimixina-vermelho de fenol. $O$ inóculo era 
FURLANETTO, S.M.P. et al. Pesquisa de alguns microrganismos em saladas com maionese adquiridas em restaurantes, lanchonetes e "rotisseries". Rev. Saúde públ., S. Paulo, 16:307-16, 1982.

espalhado sobre o ágar através de alça de Drigalski. As placas eram então incubadas à temperatura de $35^{\circ} \mathrm{C}$ por 24 a $48 \mathrm{~h}$, após o que eram selecionadas as placas contendo entre 3 e 30 colônias (APHA 1, 1976). Nestas placas procedia-se à contagem de colônias com aspecto ceroso, de cor rósea e apresentando um denso halo de precipitação. $O$ número de colônias contadas, era multiplicado por $10 \mathrm{e}$, em seguida pela recíproca da diluição correspondente, a fim de se obter - número de bactérias por grama de maionese.

Das placas de contagem, procedia-se o isolamento de colônias típicas as quais eram semeadas em ágar simples inclinado, seguido de incubação a $35^{\circ} \mathrm{C}$ por $24 \mathrm{~h}$. Em seguida eram realizadas provas bioquímicas de identificação.

Eram consideradas como cêpas típicas de $B$. cereus as que apresentavam positividade para a produção de gelatinase e amilase, redução do nitrato, prova de Voges Proskauer, fermentação da glicose, salicina, sacarose e glicerina (Thatcher e Clark 24, 1973), fermentação anaeróbia da glicose, crescimento em ágar hidrato de cloral e em caldo simples contendo $10 \%$ de $\mathrm{NaCl}$, e resultados negativos no que concerne à fermentação de arabinose, xilose e manitol (Mcssel e col.18, 1967).

Determinação do NMP de coliformes totais (Thatcher e Clark ${ }^{24}$, 1973) - De cada diluição inoculava-se $1 \mathrm{ml}$, em triplicata, em tubos contendo caldo lactosado com tubo de Durham, após o que procedia-se a incubação a $35^{\circ} \mathrm{C}$ por 24 e $48 \mathrm{~h}$. A seguir, de todos os tubos que se revelavam com prova presuntiva positiva, ou seja, com produção de gás, procedia-se à passagem em placas de ágar eosina azul de metileno (EAM de Levine) sendo estas incubadas a $35^{\circ} \mathrm{C}$ por $24 \mathrm{~h}$. De cada placa eram escolhidas 3 colônias com características das de coliformes, sendo cada uma delas semeada em dois tubos contendo, respectivamente, caldo lactosado com tubo de Durham e agar simples inclinado, os quais eram, a seguir, incubados a $35^{\circ} \mathrm{C}$. Eram consideradas como provas positivas para coliformes quando os tubos de caldo lactosado, após 24 e $48 \mathrm{~h}$, apresentavam producção de gás, e os esfregaços, feitos a partir da cultura de 24 h em ágar inclinado, mostravam a presença de bacilos Gram-negativos, não esporulados.

Determinação do NMP de E. coli (Thatcher e Clark ${ }^{24}, 1973$ ) - A partir de cada tubo de caldo lactosado, inoculado na prova presuntiva para coliformes totais e apresentando gás, era feito um repique para tubo de caldo EC, contendo tubo de Durham. Os tubos eram incubados à temperatura de $45,5^{\circ} \mathrm{C}$ por $24 \mathrm{~h}$.

Em seguida, a partir de cada tubo revelando-se com produção de gás, procedia-se à passagem da cultura em placa de ágar EAM de Levine, a qual era, posteriormente, incubada a $35^{\circ} \mathrm{C}$ por $24 \mathrm{~h}$. Findo este periodo, de cada placa eram selecionadas três colônias de bactérias fermentadoras de lactose e cada uma delas era inoculada em dois tubos contendo, respectivamente, caldo lactosado com tubo de Durham e ágar simples inclinado, os quais eram incubados a $35^{\circ} \mathrm{C}$ por 24 a $48 \mathrm{~h}$. Havendo produção de gás no caldo lactosado e somente a presença de bacilos Gram-negativos no esfregaço feito a partir das culturas de $24 \mathrm{~h}$ em agar simples inclinado, cada cêpa era semeada em tubos com água peptonada para a pesquisa da produção de indol, com meio de Clark e Lubs para a realização das provas do vermelho de metila (VM) e Voges Proskauer (VP), em ágar citrato de Simmons para a verificação do aproveitamento do citrato como fonte de carbono.

Quando as provas do indol e do VM eram positivas $e$ as de VP e do citrato negativas, considerava-se a bactéria inoculada como sendo $E$. colli.

As determinações do NMP de coliformes totais de $E$. coli eram feitas a partir do número de porções positivas respectivas $e$ usando-se a tábela de Números Mais Prováveis ${ }^{1}$. 
FURLANETTO, S.M.P. et al. Pesquisa de alguns microrganismos em saladas com maionese adquiridas em restaurantes, lanchonetes e "rotisseries". Rev. Saúde públ., S. Paulo, 16:307-16, 1982.

T A B E L A 1

Amplitude de variação e média aritmética dos números de microrganismos para 20 amostras analisadas de saladas com maionese.

\begin{tabular}{|c|c|c|c|c|}
\hline Microrganismos & Valores & Contagem/g & $\mathrm{NMP}^{*} / \mathrm{g}$ & $\begin{array}{c}\text { Média } \\
\text { aritmética/g }\end{array}$ \\
\hline $\begin{array}{l}\text { Bactérias } \\
\text { mesófilas }\end{array}$ & $\begin{array}{l}\text { Mínimo } \\
\text { Máximo }\end{array}$ & $\begin{array}{r}26.400 \\
\geqslant 30.000 .000\end{array}$ & & 13.651 .620 \\
\hline $\begin{array}{l}\text { Bactérias } \\
\text { psicrófilas }\end{array}$ & $\begin{array}{l}\text { Mínimo } \\
\text { Máximo }\end{array}$ & $\begin{array}{r}<10 \\
\geqslant 30.000 .000\end{array}$ & & $\leqslant 7.158 .200$ \\
\hline $\begin{array}{l}\text { Staphylococcus } \\
\text { aureus }\end{array}$ & $\begin{array}{l}\text { Mínimo } \\
\text { Máximo }\end{array}$ & $\begin{array}{r}<100 \\
400.000\end{array}$ & & $\leqslant 20.650$ \\
\hline $\begin{array}{l}\text { Bacillus } \\
\text { cereus }\end{array}$ & $\begin{array}{l}\text { Mínimo } \\
\text { Máximo }\end{array}$ & $\begin{array}{r}<100 \\
\geqslant 30.000\end{array}$ & & $\leqslant 2.520$ \\
\hline $\begin{array}{l}\text { Bolores e } \\
\text { leveduras }\end{array}$ & $\begin{array}{l}\text { Mínimo } \\
\text { Máximo }\end{array}$ & $\begin{array}{r}710 \\
3.700 .000\end{array}$ & & 232.750 \\
\hline $\begin{array}{l}\text { Coliformes } \\
\text { totais }\end{array}$ & $\begin{array}{l}\text { Mínimo } \\
\text { Máximo }\end{array}$ & & $\begin{array}{r}<0,03 \\
\geqslant 430.000\end{array}$ & $\geqslant 36.017$ \\
\hline $\begin{array}{l}\text { Escheriohia } \\
\text { coli }\end{array}$ & $\begin{array}{l}\text { Mínimo } \\
\text { Máximo }\end{array}$ & & $\begin{array}{r}<0,03 \\
\geqslant 24.000\end{array}$ & $\geqslant 1.676$ \\
\hline $\begin{array}{l}\text { Estreptococos } \\
\text { lecais }\end{array}$ & $\begin{array}{l}\text { Mínimo } \\
\text { Máximo }\end{array}$ & & $\begin{array}{r}<0.03 \\
\geqslant 430.000\end{array}$ & 341.002 \\
\hline
\end{tabular}

: NMP = Número Mais Provável.

Determinaf̧ão do NMP de estreptococos fecais - (Thatcher e Clark $\left.{ }^{24}, 1973\right)$ - De cada diluição eram inoculados 3 tubos de caldo dextrose-azida. Após incubação a $35^{\circ} \mathrm{C}$ por 24 e $48 \mathrm{~h}$, dos tubos com prova presuntiva positiva, ou seja, que apresentavam turvação, eram feitos repiques para tubos de caldo etil violeta-azida (EVA) a fim de se proceder à prova confirmatória. Após incubação a $35^{\circ} \mathrm{C}$ por 24 e $48 \mathrm{~h}$, eram consideradas provas confirmatórias positivas para estreptococos fecais, quando os tubos de caldo EVA se apresentavam com crescimento bacteriano evidente e formação de um sedimento de cor violeta.

A determinação do NMP de estreptococos fecais era realizada a partir do número de porções positivas e usando-se a tabela de Números Mais Prováveis ${ }^{1 .}$

Pesquisa de salmonelas (Thatcher $\mathrm{E}$ Clark ${ }^{24}$, 1973) - Eram pesadas, em duplicata, $25 \mathrm{~g}$ de salada com maionese e colocadas em 2 frascos contendo, respectivamente, caldo selenito-cistina e caldo tetrationato, os quais eram, a seguir, incubados por 24 e $48 \mathrm{~h}$ à temperatura de $35^{\circ} \mathrm{C}$. Após à incubação, a partir destas culturas, semeavam-se placas de ágar SS e ágar verde brilhante as quais eram então incubadas a $35^{\circ} \mathrm{C}$ por $24 \mathrm{~h}$. Após a incubação, selecionavam-se de cada placa algumas colônias com caracteristicas das de bactérias não fermentadoras da lactose e estas eram semeadas em tubos contendo ágar tríplice-açúcar 
FURLANetTo, S.M.P. et al. Pesquisa de alguns microrganismos em saladas com maionese adquiridas em restaurantes, lanchonetes e "rotisseries". Rev. Saude públ., S. Paulo, 16:307-16, 1982.

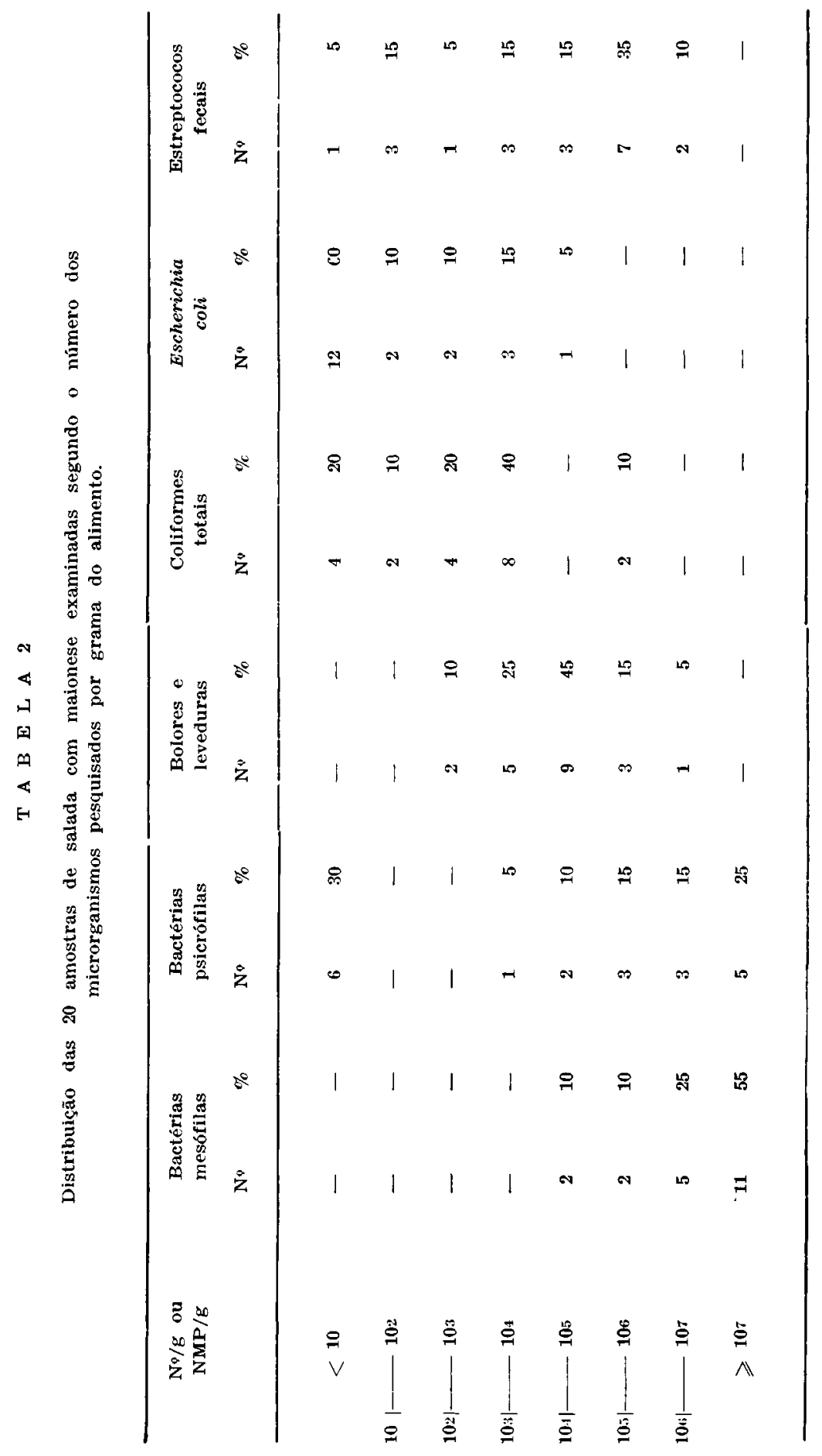


FURLANETTO, S.M.P. et al. Pesquisa de alglıns microrganismos em saladas com maionese adquiridas em restaurantes, lanchonetes e "rotisseries". Rev. Saúde pübl., S. Pavlo, 16:307-16. 1982.

T A B E L A 3

Distribuição das 20 amostras de salada com maionese examinadas segundo o número de Staphylococcus aureus e Bacillus cereus por grama do alimento.

\begin{tabular}{|c|c|c|c|c|c|}
\hline \multirow{2}{*}{\multicolumn{2}{|c|}{$\mathrm{N} \% / \mathrm{g}$}} & \multirow{2}{*}{$\begin{array}{l}\text { Staphylococcus } \\
\mathrm{N}^{\circ}\end{array}$} & \multirow{2}{*}{$\begin{array}{c}\text { aureus } \\
\%\end{array}$} & \multicolumn{2}{|c|}{ Bacillus cereus } \\
\hline & & & & Nu & $\%$ \\
\hline$<$ & $10:$ & 14 & 70 & 15 & 75 \\
\hline$I_{v}=-$ & $10:$ & 2 & 10 & 2 & 10 \\
\hline $1:---$ & $10+$ & 3 & 15 & - & - \\
\hline $1 j \cdot 1-$ & 105 & - & - & 3 & 15 \\
\hline $13 . \cdots-$ & 10 & 1 & 5 & - & - \\
\hline$\geqslant$ & 106 & - & - & - & - \\
\hline
\end{tabular}

ferro, os quais eram, a seguir, incubados a $35^{\circ} \mathrm{C}$ por $24 \mathrm{~h}$. Posteriormente, procedia-se à identificação bioquímica e sorológica das cêpas suspeitas de serem de salmonela. (Edwards e Ewing ', 1962).

\section{RESULTADOS E DISCUSSÃO}

No presente estudo as amostras de salada com maiontse examinadas revelaram-se com $\mathrm{pH}$ variando de 4,9 a 6,6. Esta foi, talvez, a razão pela qual não se obteve o isolamento de bactérias do gênero Salmonella de nenhuma das 20 amostras analisadas $e$ porque $70 \%$ delas mostraram-se com números inferiores a $10 \% / \mathrm{g}$ de $S$. aureus (Tabela 3), embora para estes dois grupos de bactérias não se faça comumente comparações quanto à sua resistência. A este respeito, salienta-se que McCroan e col.16, Khan e McCaskey ${ }^{11}$ (1973), McKinley e col.1: (1974), com base em resultados de seus estudos, concluiram que a baixa incilência de salmonelas, coliformes e estafilococos em saladas e sanduiches se deve à ação do ácido acético existente em molhos e maioneses adicionados a estes alimentos. Porém, esses autores afirmam que o efeito inibidor de bactérias patogènicas é dado não só pelo baixo $\mathrm{pH}$, mas também pelo cfeito tóxico do ácido acético presente nesses produtos. Ainda com relação ao $\mathrm{pH}$, Holtzapffel e Mossel ${ }^{\ominus}$ (1968) mostraram que salmonelas e $S$. aureus morrem em saladas de vegetais com $\mathrm{pH} 4,2$.

Rappaport e Goepfert 2" (1975) inocularam $S$. typhimurium e $S$. aureus em saladas de presunto com maionese cujo pH era da ordem de 5,3 e em saladas de frango com maionese cujo $\mathrm{pH}$ era de 5,1 a 5,3. As bactérias previamente inoculadas eram inativadás, enquanto que em saladas desses mesmos tipos de alimentos sem maionese este fenômeno não ocorria. O mesmo não se repetiu em experièncias realizadas por Lerche ${ }^{15}$ (1961) em saladas contendo carne e maionese, nas quais eram inoculadas cêpas de salmonelas. O autor verificou que, nos pequenos fragmentos de carne, as salmonelas se mantinham viáveis porque o $\mathrm{pH}$ deste alimento não chegava a ser suficientemente baixo para inativar ou inibir o crescimento dessas bactérlas.

No presente estudo obteve-se como contagem minima de $S$. aureus $<10^{2} / \mathrm{g}$, enquanto que a máxima foi de $4 \times 10^{5} / \mathrm{g}$ (Tabela 1). Estes valores foram superiores aos obtidos por Rasmunssen e Strong ${ }^{21}$ (1967) que analisando saladas de vegetais com maionese obtiveram resultados variando de zero a $2,4 \times 10^{4} \mathrm{~S}$. auteus por grama 
FURLANETTO, S.M.P. et al. Pesquisa de alguns microrganismos em saladas com maioneso adquiridas em restaurantes, lanchonetes e "rotisseries". Rev. Saúde puibl., S. Pailo, 16:307-16, 1982.

do alimento. Com relação à contagem padrão de bactérias mesófilas viáveis, e:sess autores encontraram valores compreendidos entre $6 \times 10^{2} / \mathrm{g}$ e $8,35 \times 10^{6} / \mathrm{g}$; por outro lado, o NMP de coliformes e de estreptococos fecais variaram de zero a $2,4 \times 10^{4 /} \mathrm{g}$ e de 5 a $2,4 \times 10^{4} / \mathrm{g}$, respectivamente. Estes resultados também são inferiores acs obtidos na presente investigação, pois, de acordo com a Tabela 1 os valores obtidos na contagem padrão de bactérias mesófilas variaram de $2,64 \times 10^{*} a \geqslant 3 \times 10^{\pi / g}$ de maionese, e para o NMP de coliformes e de estreptococos fecais os resultados mostraram-se compreendidos, respectivamente, entre $<0,03 \mathrm{e} \geqslant 4,3 \times 10^{5} / \mathrm{g}$ e de $<0,03$ $a \geq 4,3 \times 10^{5} / \mathrm{g}$ do alimento.

Analisando-se a Tabela 1 pode-se também verificar que a contagem de $B$. cereus variou de $<10^{2} / \mathrm{g} a \geqslant 3 \times 10^{\mathrm{H}} / \mathrm{g}$. Observa-se, ainda, que para bactérias psicrófilas esses valores variaram de $<10 / \mathrm{g}$ $a \geqslant 3 \times 10^{\circ} / \mathrm{g}$ e para bolores e leveduras de $7,1 \times 10^{2}$ a $3,7 \times 10^{6} / \mathrm{g}$ enquanto que para $E$. coli os NMP mínimo e máximo foram de $<0,03$ e de $\geqslant 2,4 \times 10^{4 / g}$.

Analisando-se a Tabela 2 pode-se constatar que para bactérias mesófilas todas as amostras examinadas revelaram-se com número igual ou superior a $10^{4 / g}$, salientando-se que em 16 amostras $(80 \%)$ os números contados foram muito altos, ou seja, de $10^{6}$ ou mais por grama, indicando a ocorrência de contaminação provavelmente durante o processo de manipulação do alimento. Por outro lado, a grande maioria $(70 \%)$ das amostras mostrou-se com $10^{3}$ ou mais bactérias psicrófilas por grama, sendo que em 8 amostras (40\%) os números contados foram de $10^{\circ}$ ou mais bactérias por grama; tais resultados sugerem que mesmo o produto sendo mantido a temperatura de geladeira a sua deterioração poderia ocorrer em um tempo relativamente curto, dada a alta quantidade de bactérias psicrófilas existentes.

Com relação a contagem de bolores $e$ leveduras, estas revelaram-se sempre com número igual ou superior a $102 / \mathrm{g}$ de salada com maionese sendo que a maioria $(65 \%)$ continha $10^{4}$ ou mais destes microrganismos por grama do produto.

Das amostras analisadas, em $16(80 \%)$ constatou-se a presença de bactérias coliformes totais, assim como de E. coli $8(40 \%)$ e de estreptococos fecais 19 (95\%) indicando que o alimento em algum instante sofreu poluição de origem fecal. Cumpre salientar que, havendo poluição fecal, bactérias patogênicas de origem intestinal podem estar também prcsentes no alimento, as quais, se conseguirem resistir à acidez do produto, poderão representar risco à saúde do consumidor.

$\mathrm{Na}$ Tabela 3 , pode-se verificar que os números de $B$. cereus encontrados foram de forma geral baixos, pois $75 \%$ das amostras examinadas revelaram-se com números superiores a $10^{2} / \mathrm{g}$ para essa bactéria.

\section{CONCLUSÕES}

1. Das 20 amostras de saladas com maionese examinadas, $16(80 \%)$ revelaram resultados positivos para coliformes totais, $8(40 \%)$ para $E$. coli e $19(95 \%)$ para estreptococos fecais.

2. Os valores obtidos na contagem padrão de bactérias mesófilas variaram de $2,64 \times 10^{4} \mathrm{a}>3 \times 10^{-} / \mathrm{g}$ do produto.

3. A contagem de bactérias psicrótilas variou de $<10 / \mathrm{g} a \geqslant 3 \times 10^{\pi} / \mathrm{g}$.

4. Na contagem de S. aureus em $30 \%$ das amostras as contagens estiveram compreendidas entre $<10^{2}$ e $10^{6} / \mathrm{g}$ do alimento.

5. Na contagem de B. cereus em $25 \%$ das amostras os números variaram de $<10^{2} a \geq 3 \times 10^{ \pm} / \mathrm{g}$.

6. Para bolores e leveduras as contagens oscilaram entre $7,1 \times 10^{2}$ e $3,7 \times$ $10^{6 / \mathrm{g}}$.

7. Todas as amostras revelaram-se negativas para bactérias do gênero Salmonella. 
FURLANETTO, S.M.P. et al. Pesquisa de alguns microrganismos em saladas com maionese adquiridas em restaurantes, lanchonetes e "rotisseries". Rev. Saúde públ., S. Paulo, 16:307-16, 1982.

8. Os valores obtidos nas contagens dos vários grupos de microrganismos pesquisados podem ser considerados altos em várias amostras, os quais podem ser resultado de más condições sanitárias das hortaliças e/ou manipulação e/ou conservação do alimento realizadas em condições não satisfatórias.

FURLANETTO, S.M.P. et al. [Research into microrganisms in mayonnaise salad obtained in restaurants, snack bars and "rotisseries"]. Rev. Saúde gúbl., S. Paulo, 16:307-16, 1982.

ABSTRACT: Twenty samples of mayonnaise salads obtained in restaurants, snack bars and "rotisseries" were analysed for total plate count of mesophilic and psichrophilic bacteria, yeasts and molds, enumeration and isolation of Staphylococcus aureus, Bacillus cereus, the MPN of totally coliform bacteria, Escherichia coli and fecal streptococci as well as for investigation into the occurrence of Salmonella. It was found, in total counts, of coliform and streptococci, that numbers were high in many samples, showing the occurrence of contamination probably during the handling of the food. All the analysed samples were positive to total coliforms as well as to Escherichia coli and fecal streptococci showing that the food had, at some point, suffered pollution of fecal origin. Staphylococcus aureus and Bacillus cereus in varying proportions were found in different samples. All the samples were showed to be negative for Salmonella.

UNITERMS: Food contamination. Food microbiology.

\section{REFERENCIAS BIBLIOGRAFICAS}

1. AMERICAN PUBLIC HEALTH ASSOCIATION. Compendium of methods for the microbiological examination of foods. Washington, D.C., 1976.

2. APLEMAN, M.D, et al. An investigation of a mayonnaise spoilage. Food Technol., $3: 201-3,1949$.

3. BAIRD-PARKER, A.C. Methods for classifying staphylococci and micrococci. In: Gibbs, B.M. \& Skinner, F.A. Identification methods for microbiologists. London, Academic Press, 1966. p. 59-64.

4: BRODHAGE, H. \& ANDERHUB, B. Hygiene in catering. In: Hobbs, B.C. \& Christian, J.H.B. The microbiological safety of food. 2nd ed. London, Academic Press, 1975. p. 47-8.

j. DI SALVOo, G.W. Desoxyrribonlclease and coagulase activity of micrococci. Med. Techn. Bull., 9:191-6, 1958.
6. EDWARDS, P.R. \& EWING, W.H. Identification of enterobacteriaceae. 2nd ed. Minneapolis, Burgess Publishing, 1962. p. 92-187.

7. FABIAN, F.W, \& WETHINGTON, M.C. Bacterial and chemical analyses of mayonnaise, salad dressing, and related products. Food Res., 15:138-45, 1950.

8. FABIAN, F.W. \& WETHINGTON, M.C. Spoilage in salad and french dressing due to yeast. Food Res., $15: 135-7,1950$.

9. HoitzapFFel, D. \& MOSSEL, D.A.A. The survival of pathogenic bacteria and the microbial spoilage of saleds containing $\mathrm{m}$ zat, fish and vegetables. $J$. Food Technol., 3:233-9, 1968.

10. KERELUK, K. \& GUNDERSON, M.F. Studies on the bacteriological quantity of frozen meat pies. I - Bacteriologica! survey of some commercially frozen meat pies. Appl. Microbiol., 7:320-3, 1959. 
FURLANetTo, S.M.P. et al. Pesquisa de alguns microrganismos em saladas com maionese adquiridas em restaurantes, lanchonetes e "rotisseries". Rev. Saude públ., S. Paulo, 16:307-16, 1982.

11. KHAN, N.A. \& McCASKEY, T.A. Incidence of salmonellae in commercially prepared sandwiches for the vending trade. $J$. milk Food Technol., 36:315-6, 1973.

12. KINTNER, T.C. \& MANGEL, M. Survival of staphylococci and salmonellae experimentally inoculated into salad dressing prepared with dried eggs. Food Res., $18: 6-10,1953$.

13. KOTAKA, P.I. et al. Surto de toxi-infecçăo alimentar, ocorrido em Curitiba Paraná/1978. Bol. epidem., Rio de Janeiro, 11:49-56, 1979.

14. KURTZMAN, C.P. et al. Microbiological spoilage of mayonnaise and salad dressings. Appl. Microbiol., 21:870-4, 1971.

15. LERCHE, M. Zur lebensfahigkeit von salmonellakterien in mayonnaise und fleischsalat. Wien. tierärztl. Mschr, 48:348$-61,1961$.

16. McCROAN, J.E. et al. Staphylococcus and salmonellae in commercial wrapped sandwiches. Publ. Hith Rep., 79:997-1004, 1964.

17. MickINLEY, T.W. et al. Staphylococcal growth and enterotoxim production in chicken and chicken salad. Quart. Bull. Ass. Food Drug off. U.S., 38:56, 1974.

18. MOSSEL, D.A.A. et al. Enumeration of Bacillus cereus in foods. Appl. Microbiol., $15: 650-3,1967$.

19. PERDENSON, C.S. Bacterial spoilage of a Thousand Island dressing. J. Bact., 20: 99-106, 1930.
20.RAPPAPORT, H. \& GOEPFERT, J.M. Behavior of Salmonella and Staphylococcus aureus: annual report. Madison, Wis., Food Research Institute, 1975.

21. RASMUSSEN, C.A. \& STRONG, D.H. Bacteria in chilled delicatessen foods. Publ. Hith Rep., 82:353-9, 1967.

22. SMITTLE, R.B. Microbiology of mayonnaise and salad dressing: a review. J. Food Protec,, 40:415-22, 1977.

23. SUBCOMMITTEE on Taxonomy of Staphylococci and Micrococci. Minutes of First Meeting (5th - 6th October, 1964), Int Bull. bact. Nomencl., 15:107-8, 1965.

24. THATCHER, F.S. \& CLARK, D.S. Analises microbiologico de los alimentos. Zaragoza, Ed. Acribia, 1973. p. 70-169.

25. VLALDIMIROV, B.D. \& NEFEDIEVA, N.P. Mayonnaise as culture medium for microorganisms. Voprosy Pitaniya, 6:85-96, 1937, Apud Chem. Abstr., 32:7955, 1938.

26. WETHINGTON, M.C. \& FABIAN, F.W. Viability of food poisoning staphylococe and salmonellae in salad dressing and salmonellae in salad dressing and mayon. naise. Food Res., 15:125-34, 1950.

27. ZELANTE, F. Contribuição para o estudo de Staphylococcus isolados de canais radiculares. São Paulo, 1974. [Tese de Livre-Docência - Instituto de Ciências Biomédicas da USP].

Reccbido para sublicą̧ão em 19/11/1981 Aprovado para publicaçāo em 16/08/1982 